\title{
REVISÃO SISTEMÁTICA SOBRE A RESPOSTA AO TRATAMENTO DA HEPATITE B CRÔNICA E OS DADOS EPIDEMIOLÓGICOS DOS PACIENTES
}

\author{
$\underline{\text { Abraão dos Santos Souza }}{ }^{1}$; Bruna Moreira Aguiar $^{2}$ e Erenilde Marques de Cerqueira ${ }^{3}$ \\ 1. Bolsista PROBIC/UEFS, Graduando do curso de Medicina, Universidade Estadual de Feira de Santana, e-mail: \\ abraaossouza@hotmail.com \\ 2. Bolsista PROBIC/UEFS, Graduando do curso de Medicina, Universidade Estadual de Feira de Santana, e-mail: \\ brunna.aguiar@gmail.com \\ 3. Orientadora, Departamento de Saúde, Universidade Estadual de Feira de Santana, e-mail: eremarques@ fsonline.com.br
}

PALAVRAS-CHAVE: Hepatite; Epidemiologia; Tratamento.

A hepatite B (HB) é um problema mundial de saúde, atingindo cerca de dois bilhões de pessoas por todo mundo com aproximadamente 350 milhões de portadores crônicos, principalmente em países em desenvolvimento (Lopes \& Schinoni, 2011; Projeto Diretrizes, 2009).

A hepatite B é decorrente da infecção pelo vírus da hepatite B (VHB) da familia hepadnaviridae, que tem por preferência infectar as células hepáticas (Lopes \& Schinoni, 2011). É uma partícula esférica com invólucro interno e externo e com o DNA viral em seu interior. O invólucro externo é composto por proteínas, glicoproteínas e lipídeos que, alguns destes constituintes fazem parte dos meios de diagnóstico. (Ferreira, 2000; Lopes \& Schinoni, 2011).

Dos pacientes com $\mathrm{HB}, 8$ a $10 \%$ cronificam em decorrência do escape do vírus às defesas do sistema imune do paciente (Lopes \& Schinoni, 2011). Diferente de outras hepatites, ela possui vacina como forma de prevenção, porém, o descaso com as doses a serem tomadas e o inadequado acompanhamento clínico do paciente com a doença em fase inicial propiciam a continuada disseminação do vírus (Ferreira \& Silveira, 2004; Projeto Diretrizes, 2009).

Da população brasileira, segundo o Ministério da Saúde (MS), 15\% já tiveram contato com o VHB e destes, 1\% desenvolvem a doença crônica (Brasil, 2005). De forma silenciosa o vírus vai sendo disseminado por indivíduos que, em maioria assintomáticos, descobrem - se portadores a partir da doação de sangue.

O presente tem como objetivo revisar de forma sistemática a resposta ao tratamento da Hepatite B Crônica e os dados epidemiológicos dos pacientes portadores.

\section{METODOLOGIA}

Foi realizada uma revisão sistemática de literatura na base de dados da SCIELO. Foram feitas duas procuras, uma para avaliar a resposta ao tratamento e outra para avaliar os dados epidemiológicos. Conforme os termos de busca presentes nos Descritores em Ciências e Saúde, a primeira pesquisa foi com as seguintes palavras chaves: Hepatite B crônica, Tratamento, Brasil OR Brazil e AND NOT Revisão OR Review; e a segunda com: Hepatite B crônica e variáveis sócio-demográficas.

\section{ANÁLISE E DISCUSSÃO DOS RESULTADOS}

As pesquisas tiveram como resultado a seleção de 15 artigos. Destes, um foi repetido, 11 foram excluídos por leitura de título e resumo, sendo três selecionados para leitura completa (tabela 1). Os artigos selecionados para análise foram: pesquisas originais que avaliassem o tratamento e os dados epidemiológicos dos pacientes com Hepatite B Crônica, escritos em inglês, português ou espanhol, sem restrições de ano de publicação. Foram excluídos artigos de acesso restrito ou os de revisões bibliográficas. 


\begin{tabular}{|c|c|c|c|}
\hline $\begin{array}{l}\text { Primeir } \\
\text { o autor }\end{array}$ & Ano & Objetivo & Resultados/Conclusão \\
\hline $\begin{array}{l}\text { VIEIRA } \\
\text {, GD }\end{array}$ & 2015 & $\begin{array}{l}\text { Avaliar dados epidemiológicos e } \\
\text { a distribuição espacial dos casos } \\
\text { de hepatite B notificados no } \\
\text { Estado de Rondônia no período } \\
\text { de } 2002 \text { a } 2012 \text {. }\end{array}$ & 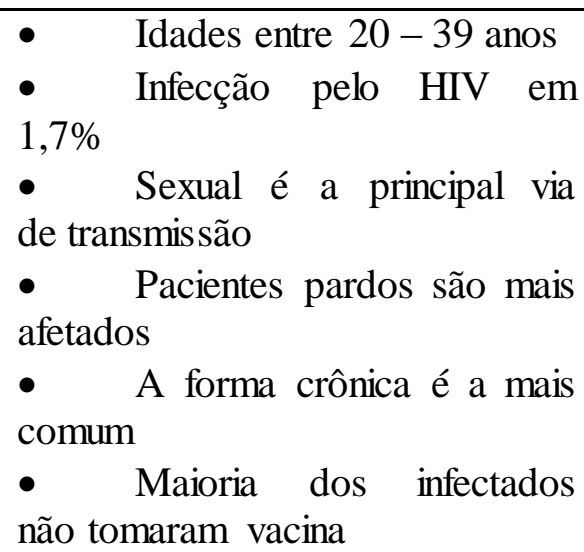 \\
\hline $\begin{array}{l}\text { CRUZ, } \\
\text { CRB }\end{array}$ & 2009 & 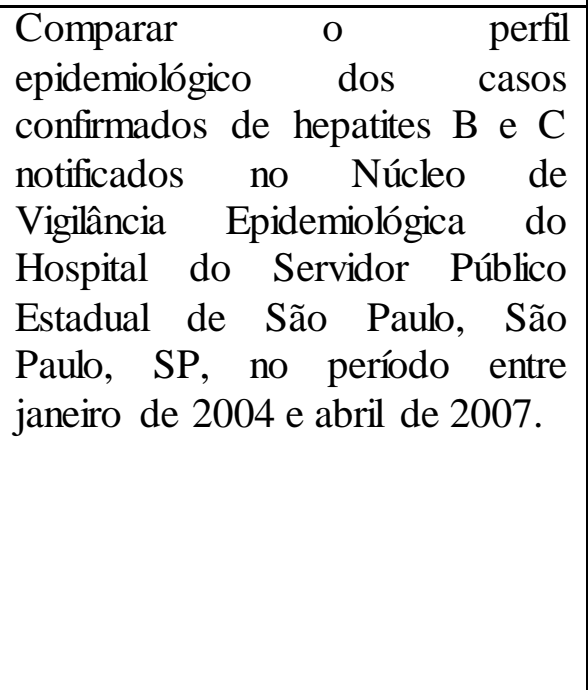 & $\begin{array}{l}\text { - Sexo masculino mais } \\
\text { prevalente na hepatite B } \\
\text { - Faixa etária mais de } 40 \text { a } \\
54 \text { anos } \\
\text { - A escolaridade não teve } \\
\text { importância estatística } \\
\text { - Houve predomínio de não } \\
\text { vacinados } \\
\text { - Antecedente de doenças } \\
\text { sexualmente } \\
\text { transmissíveis teve } \\
\text { importância estatística } \\
\text { Transmissão sexual foi a } \\
\text { mais frequente }\end{array}$ \\
\hline $\begin{array}{l}\text { Souto, } \\
\text { FJD }\end{array}$ & 2007 & $\begin{array}{l}\begin{array}{l}\text { Descrever } \\
\text { pacientes em }\end{array} \text { tratamento com } \\
\text { lamivudina } \\
\text { prolongado no no ambulatório de } \\
\text { Hepatologia do Hospital da } \\
\text { Universidade Federal de Mato } \\
\text { Grosso (UFMT), em Cuiabá, } \\
\text { que funciona como referência } \\
\text { para a região. }\end{array}$ & $\begin{array}{l}\text { - } \text { Sexo masculino mais } \\
\text { prevalente na hepatite B } \\
\text { - } \quad \text { Idade média de } 43 \text { anos } \\
\text { - } \quad \text { A maioria }(67 \%) \text { dos } \\
\text { pacientes apresentou } \\
\text { resposta bioquímica à } \\
\text { lamivudina }\end{array}$ \\
\hline
\end{tabular}

As idades de acometimento dos pacientes variaram da $3^{\text {a }}$ até a $6^{\text {a }}$ década e que o histórico de outras infecções sexualmente transmissíveis teve relevância estatística. Associado a isto, a via sexual apresentou-se como a principal via de transmissão e o sexo masculino e os pacientes pardos foram os mais afetados. Dentre infectados, os pacientes que não tomaram vacina representaram a sua maioria, o que pode sugerir uma maior susceptibilidade destes.

Somente um estudo avaliou a resposta ao tratamento da hepatite B crônica. Este estudo avaliou a resposta ao tratamento com lamivudina, sendo que $67 \%$ dos pacientes tratados com esta droga alcançaram boa resposta bioquímica com normalização das aminotransferases (enzimas hepáticas).

\section{CONCLUSÕES}


Observa-se pacientes em idade adulta, do sexo masculino, pardo, sexualmente ativo e não vacinadas como o perfil epidemiológico mais comum dos infectados crônicos do vírus da hepatite B.

Quanto ao tratamento, somente um estudo avaliou a resposta ao tratamento dos pacientes com hepatite B crônica, o que fortalece a iniciativa de concluir a pesquisa com os pacientes da cidade de Feira de Santana - Bahia a respeito de sua resposta ao tratamento.

\section{REFERÊNCIAS}

BRASIL. Ministério da Saúde. Secretaria de Vigilância em Saúde. Departamento de Vigilância Epidemiológica. Manual de aconselhamento em hepatites virais / Ministério da Saúde, Secretaria de Vigiância em Saúde, Departamento de Vigilância Epidemiológica. Brasilia : Ministério da Saúde, 2005.

CRUZ, C.R.B; M. M. SHIRASSU; W. P. MARTINS. 2009. Comparação do perfil epidemiológico das hepatites $\mathrm{B}$ e $\mathrm{C}$ em um serviço público de São Paulo. Arquivos de Gastroenterologia, p. 225-229.

FERREIRA M.S. 2000. Diagnóstico e tratamento da hepatite B. Revista da Sociedade Brasileira de Medicina Tropical. 33(4): 389-400

FERREIRA C.T; T.R. SILVEIRA. 2004. Hepatites virais: aspectos da epidemiologia e da prevenção. Rev. bras. Epidemiol. 7(4): 473-487.

LOPES, T.G.S.L; M.I.L. SCHINONI. 2011. Aspectos gerais da hepatite B. R. Ci. med. biol., Salvador. 10(3): 337-344.

SOUTO, F.J.D; A.C.S. PIRAJÁ; G.S. SILVA; M. BOTTECCHIA; S.A. GOMES. 2007. Lamivudina por tempo prolongado no tratamento da hepatite B crônica no estado de Mato Grosso. Revista da Sociedade Brasileira de Medicina Tropical, p. 18-24.

PROJETO DIRETRIZES. 2009. Hepatite B Crônica: Tratamento. Homepage: http://sbn.org.br/app/uploads/34-Hepatite.pdf

VIEIRA, G.D; M. FLORÃO; K.P.O. CASTRO; T.C. ALVES; S. VAICIUNAS; E.R. HONDA; L.M.A. CAMARGO; C.M. SOUSA. 2015. HEPATITIS B IN RONDÔNIA (WESTERN AMAZON REGION, BRAZIL): descriptive analysis and spatial distribution. Arquivos de Gastroenterologia, p. 18-21. 